\title{
Therapeutic responses to different anti-Trypanosoma cruzi drugs in experimental infection by benznidazole-resistant parasite stock
}

\author{
SÉRGIO CALDAS ${ }^{1,2}$, IVO SANTANA CALDAS ${ }^{1,3}$, ALZIRA BATISTA CECÍLIO ${ }^{2}$, \\ LÍVIA DE FIGUEIREDO DINIZ ${ }^{1}$, ANDRÉ TALVANI ${ }^{1}$, ISABELA RIBEIRO ${ }^{4}$ \\ and MARIA TEREZINHA BAHIA ${ }^{1} *$ \\ ${ }^{1}$ Laboratório de Doença de Chagas, Departamento de Ciências Biológicas and Núcleo de Pesquisas em Ciências Biológicas, \\ Universidade Federal de Ouro Preto, Campus Universitário, Morro do Cruzeiro, Ouro Preto, MG, 35400-000, Brazil \\ ${ }^{2}$ Fundação Ezequiel Dias, Rua Conde Pereira Carneiro, 80, Gameleira, Belo Horizonte, Minas Gerais, Brazil \\ ${ }^{3}$ Departamento de Patologia e Parasitologia, Instituto de Ciências Biomédicas, Universidade Federal de Alfenas, Alfenas, \\ $M G$, Brazil \\ ${ }^{4}$ Drugs for Neglected Disease initiative (DNDi), 1202 Geneva, Switzerland
}

(Received 21 fanuary 2014; revised 15 April 2014; accepted 7 May 2014; first published online 21 fuly 2014)

SUMMARY

This study describes the role of parasite clearance time induced by benznidazole, fexinidazole and posaconazole treatments upon mice infection with a benznidazole-resistant Trypanosoma cruzi strain in the pathological outcomes. Trypanosoma cruzi-infected mice were treated with different drugs and parasite clearance time was detected by blood and tissue $\mathrm{qPCR}$, to determine the dynamic relationship between the efficacy of the treatments and the intensity of heart lesion/serum inflammatory mediators. Our results indicate that anti-T. cruzi treatments were able to reduce parasite replication and consequently induce immunomodulatory effects, where the degree of the immunopathology prevention was related to the time of parasite clearance induced by different treatments. Nevertheless, in benznidazole and posaconazole treatments, parasite rebounding was detected with parasitism reaching levels similar to infected and non-treated mice; the time for parasitic rebound being earlier among benznidazole-treated mice. In parallel, an increase of cardiac lesions and plasma chemokine levels was also detected and was more accentuated in benznidazole-treated animals. Interestingly, in the presence of parasitological cure (fexinidazole treatment), basal levels of these inflammatory mediators were evidenced as well as an absence of cardiac inflammation or fibrosis. Overall, our data indicate that all treatments have positive effects on the clinical evolution of $T$. cruzi infection, with success in preventing cardiac alterations being drug-dependent.

Key words: Trypanosoma cruzi, real-time PCR, chemotherapy, inflammation, benznidazole, posaconazole, fexinidazole.

\section{INTRODUCTION}

Chemotherapy for Chagas disease remains unsatisfactory in terms of both toxicities and lack of effectiveness. There is a growing consensus that the persistence of the parasite, together with the imbalance of host immune response, leads to a sustained inflammatory response that underlies the characteristic lesions of the infection. Machado et al. (2008) demonstrated that cardiomyocytes are a potential source of cytokines, chemokines and nitric oxide $(\mathrm{NO})$ in vivo. In mice infection, these factors may contribute to the recruitment, placement and migration of inflammatory cells in heart tissue, leading to the persistence of myocarditis. Chemokines such as CCL2 have emerged as critical in infections and autoimmune myocarditis (Paiva et al. 2009). Specially in Trypanosoma cruzi infection, this

* Corresponding author: Laboratório de Doença de Chagas, sala 39, Instituto de Ciências Biológicas, ICEB II, Universidade Federal de Ouro Preto, Ouro Preto, MG, 35400-000, Brazil. E-mail: mtbahia@nupeb.ufop.br chemokine is intensely produced in the heart of infected mice and its involvement in parasitic uptake and destruction by macrophage has been demonstrated (Aliberti et al. 1999; Machado et al. 2000; Paiva et al. 2009). Another chemokine observed in macrophages and cardiomyocytes infected with T. cruzi is CCL5, and in several studies the role of this chemokine in attracting leucocytes and its probable involvement in controlling the growth of T. cruzi and NO production have been described (Sallusto et al. 1998; Aliberti et al. 1999; Cook et al. 1999; Machado et al. 2000; Talvani et al. 2000). These findings suggest that eradication of the parasite may be a prerequisite to contain the development of Chagas disease, preventing its irreversible long-term consequences. Thus, the identification of new drugs and assessing the impact of antiparasitic treatment on the prevention of morbidity for infected individuals remain as major challenges in health promotion and disease control (Urbina, 2010).

Current drugs for Chagas disease, such as nifurtimox and benznidazole, require long-term 
administration and often show efficacy problems, including insufficient activity in established, chronic forms of the disease (Cançado, 2000). However, nitroheterocyclics are a well-known class of pharmacologically active compounds that deserve special attention for the treatment of infectious diseases. The antimicrobial toxicity of nitroimidazoles is dependent on reduction by nitroreductases of the nitro group that generate cytotoxic species that cause damage to DNA, lipids and proteins (Do Campo and Moreno, 1986; Hall and Wilkinson, 2011). Fexinidazole, a 2-substituted 5-nitroimidazole, was originally synthesized by Hoechst in the 1970s, and has recently been identified as a promising new drug candidate for treatment of African trypanosomiasis (Torreele et al. 2010). Fexinidazole has previously been shown to act in vivo against T. cruzi (Raether and Seidenath, 1983). These results were confirmed by Bahia et al. (2012) where the authors demonstrated that treating mice with fexinidazole cured acute and chronic experimental T. cruzi infection and the efficacy of this drug was equivalent in benznidazole susceptible and resistant parasite stocks.

New treatment options also include inhibitors of the sterol biosynthesis pathway, in particular C14- $\alpha$ demethylase inhibitors such as posaconazole and ravuconazole that represent promising target drugs (Molina et al. 2000; Diniz et al. 2010, 2013). It has been argued that the in vivo antiparasitic activities of these compounds are a result of a combination of their potent and selective intrinsic anti-T. cruzi activity and their pharmacokinetic properties, such as long terminal half-life and large volumes of distribution (Urbina, 2010).

Natural resistance of some T. cruzi strains to nitroderivative compounds might explain therapeutic failure in Chagas disease. However, drug-induced reduction of the parasite loads in infected tissues can exert positive effects in the clinical evolution of Chagas disease by reducing the associated inflammatory processes. In order to further characterize the role of parasite clearance time induced by different treatments in mice infected with a resistant T. cruzi VL-10 strain and the outcome of these treatments in the development of the acute and chronic phases of experimental Chagas disease, we used the blood and tissue qPCR to determine the dynamic relationship between the efficacy of the treatment with posaconazole, fexinidazole and benznidazole and the heart lesion/serum inflammatory mediators in experimental hosts.

\section{MATERIALS AND METHODS}

\section{Animal model and parasite strain}

Female Swiss mice from the Animal Facility at Federal University of Ouro Preto (UFOP) were used in this study. Animals were fed with commercial food, and water was available ad libitum. Swiss mice $(18-22 \mathrm{~g})$ were inoculated intraperitoneally with $5 \cdot 0 \times 10^{3}$ bloodstream trypomastigotes of the VL-10 T. cruzi strain, DTU II, which is resistant to the benznidazole-treatment (Filardi and Brener, 1987).

\section{Study drugs}

Benznidazole: N-Benzyl-2-(2-nitro-1H-imidazol1-yl) acetamide (produced by LAFEPE, Brazil), was administered orally in a water suspension with $0 \cdot 5 \% \mathrm{w} / \mathrm{v}$ methyl cellulose; fexinidazole: 1 -Methyl-2$\{[4-($ methylsulfanyl)phenoxy $]$ methyl $\}-5-$ nitro- $1 \mathrm{H}-$ imidazole, was administrated orally in suspension containing methyl cellulose $0.5 \% \mathrm{w} / \mathrm{v}$, with $5 \% \mathrm{v} / \mathrm{v}$ of polysorbate 80 ('Tween 80 ) and posaconazole: 4-\{4[4-(4-\{[(5R)-5-(2,4-difluorophenyl)-5-(1H-1,2,4triazol-1-ylmethyl)oxolan-3-methyl]methoxy phenyl) piperazin-1-yl]phenyl $\}$-1 -[(2S,3S)-2-hydroxypentan3-yl]-4,5-dihydro-1H-1,2,4-triazol-5-one; Noxafil ${ }^{\circledR}$, Schering-Plough) was diluted in ultrapure water and administered orally.

\section{Determination of treatment efficacy by parasite quantification}

The first set of experiments was designed to determine the kinetics of the parasite clearance induced by benznidazole, fexinidazole and posaconazole in mice infected with VL-10 strain. Groups of 30 infected mice were treated with the different compounds. The drugs were administered at the time of parasitaemia detection, which occurred at day 10 post-inoculation, for 20 consecutive days at the doses determined in previous studies. Benznidazole was administered at a dose of $100 \mathrm{mg} \mathrm{kg}^{-1} \mathrm{day}^{-1}$ (Filardi and Brener, 1987), fexinidazole at a dose of $300 \mathrm{mg} \mathrm{kg}^{-1} \mathrm{day}^{-1}$ (Bahia et al. 2012) and posaconazole at a dose of $20 \mathrm{mg} \mathrm{kg}^{-1} \mathrm{day}^{-1}$ in two daily doses (Molina et al. 2000). A group of 30 animals infected with the parasite but receiving no treatment and 30 healthy mice treated with the different compounds were used as controls.

The kinetics of parasite clearance was investigated in peripheral blood and in cardiac muscle tissue samples. For blood evaluation, animals were bled at $10,12,14,16,20,30,40,50,60$ and 120 days of infection (di) and parasite quantification was performed by microscopic fresh blood examination (FBE) and qPCR assays. For parasite tissue quantification, groups of 6 animals were euthanized at 10,16, 30, 60 and $120 \mathrm{di}$ and parasite quantification was performed in $30 \mathrm{mg}$ of heart muscle tissue by qPCR. For FBE, the animals were bled from the tail vein, $5 \mu \mathrm{L}$ of collected blood were used to estimate the number of parasites as described by Brener (1962). For the qPCR assay, animals were bled from the orbital venous sinus and $200 \mu \mathrm{L}$ of collected blood was mixed with $35 \mu \mathrm{L}$ of sodium citrate solution at $129 \mathrm{~mm}$ (DOLES, BR) and used for DNA extraction. 
DNA extraction was performed using the Wizard ${ }^{\circledR}$ Genomic DNA Purification Kit (Promega) with some modifications (Caldas et al. 2012). Assays of qPCR were performed using the SYBR Green system (Roche Applied Science, Mannheim, Germany) according to the manufacturer's instructions and using the primers TCZ-F 5'-GCTCTTGCCC ACAMGGGTGC-3', where $\mathrm{M}=\mathrm{A}$ or $\mathrm{C}$ and TCZ R 5'-CCAAGCAGCGGATAGTTCAGG-3' (Invitrogen $^{\mathrm{TM}}$ ) for T. cruzi DNA amplification (Cummings and Tarleton, 2003). The internal control (corresponding to a segment of the murine TNF- $\alpha$ gene) was amplified using the primers TNF-5241 5'-TCCCTCTCATCAGTTCTATG GCCCA-3' and TNF-5411 5'-CAGCAAGCA 'TCTATGCACTTAGACCCC-3' (Invitrogen ${ }^{\mathrm{TM}}$ ) (Cummings and Tarleton, 2003). Cycles of amplification were carried out in StepOnePlus real-time PCR System, Applied Biosystems. The cycles consisted of an initial denaturation hold of $10 \mathrm{~min}$ at $95^{\circ} \mathrm{C}$ followed by 40 cycles of $15 \mathrm{~s}$ at $94^{\circ} \mathrm{C}$ and $1 \mathrm{~min}$ at $64 \cdot 3{ }^{\circ} \mathrm{C}$ with fluorescence acquisition. Amplification was immediately followed by a melt programme with an initial denaturation for $15 \mathrm{~s}$ at $95^{\circ} \mathrm{C}$, cooling to $60^{\circ} \mathrm{C}$ for $1 \mathrm{~min}$ and then a stepwise temperature increase of $0 \cdot 3{ }^{\circ} \mathrm{C} \mathrm{s}^{-1}$ from 60 to $95^{\circ} \mathrm{C}$. All samples were analysed in duplicate and the mean quantification values for $T$. cruzi DNA were normalized by the data obtained with the murine-specific ( TNF- $\alpha$ ) primers. Standard curves were performed using 5 -fold serial dilutions of an initial suspension of $5 \times 10^{6}$ parasites $/ 0 \cdot 1 \mathrm{~mL}$ of mice blood (for $\mathrm{qPCR}$ in blood) or $10^{6}$ parasites $/ 30 \mathrm{mg}$ of heart muscle tissue (for qPCR in tissue). Negative samples and reagent controls were processed in parallel in each assay, and all experiments were conducted under controlled conditions.

\section{Myocardial tissue assessment}

For morphometric analysis, mice were euthanized at 10, 30 and $120 \mathrm{di}$ (6 animals/group/day) and heart tissues fixed with $10 \%$ formalin and embedded in paraffin. Blocks were cut into $4 \mu \mathrm{m}$ sections and stained by hematoxylin-eosin (H\&E) for inflammation assessment (10, 30 and $120 \mathrm{di})$ or Masson's trichromic for fibrosis quantitative evaluation (120 di). Twenty fields from H\&E or Masson's trichromic slides were randomly chosen at $40 \times$ magnification for a total of $74931 \mu \mathrm{m}^{2}$ analysed myocardium area. Images were captured using a Leica DM 5000 B microcamera (Leica Application Suite, model $2 \cdot 4 \cdot 0 \mathrm{R} 1)$ and processed by the software Leica Qwin V3 image analyser.

\section{CCL2, CCL5 and NO levels}

For immunoassays, animals were bled at 10, 30 and 120 di. Plasma levels of CCL2 and CCL5 were measured by ELISA using commercially available antibodies and according to the procedures supplied by the manufacturer (DuoSet ${ }^{\circledR}$ ELISA Development System, RandD Systems ${ }^{\circledR}$, Minneapolis, MN systems). ELISA measurements for a given experiment were conducted in duplicate in the same plate. Results were expressed as pg $\mathrm{mL}^{-1}$ and the detection limits of the ELISA assays were in the range of 250-3.9 $\mathrm{pg} \mathrm{mL}^{-1}$ for CCL2 and 2000-31.25 $\mathrm{pg} \mathrm{mL}^{-1}$ for CCL5.

Nitric oxide production was evaluated by nitrite measurement, and its stable degradation product by the Griess reaction. Total nitrite/nitrate levels were determined by the conversion of nitrate to nitrite using nitrate reductase in the presence of reduced nicotinamide adenine dinucleotide phosphate and flavinadenine dinucleotide. After centrifugation each plasma sample $(50 \mu \mathrm{L})$ was added to $50 \mu \mathrm{L}$ of the Griess solution (1\% sulfanilamide, $0 \cdot 1 \% \quad N-(1-$ Naphthyl) ethylenediamine dihydrochloride, $2 \cdot 5 \%$ $\mathrm{H}_{3} \mathrm{PO}_{4}$ ). Absorbance was measured at $550 \mathrm{~nm}$ in the microplate ELISA reader (model 680, BioRad). Nitrite concentrations were determined by using a standard sodium nitrite curve from 125 to $1 \mu \mathrm{M}$.

\section{Statistical analysis}

Data were expressed as mean \pm S.D. Statistical difference for parasitological data among groups of mice at different days, as well as cytokine levels and intensity of cardiac inflammation and fibrosis, were determined by the non-parametric Kruskal-Wallis test. Values of $P<0.05$ were considered significant.

\section{RESULTS}

In the first set of experiments, we evaluated the clearance time of parasites induced by fexinidazole, posaconazole and benznidazole treatments in Swiss mice infected with $T$. cruzi stock that was resistant to benznidazole. Infection of Swiss mice with the VL-10 strain resulted in an acute parasitaemic phase easily detectable by FBE from 10 to $30 \mathrm{di}$, peaking at $16 \mathrm{di}$ with average levels of $8 \cdot 2 \times 10^{5}$ parasites $/ 0 \cdot 1 \mathrm{~mL}$ of blood. Similar results were observed in the blood and cardiac tissue using qPCR assay, since a higher parasite load was detected in blood $\left(5 \cdot 6 \times 10^{5}\right.$ parasites $/ 0 \cdot 1 \mathrm{~mL})$ and heart tissue $\left(2 \cdot 6 \times 10^{4}\right.$ parasites/ $30 \mathrm{mg}$ of tissue) samples at $16 \mathrm{di}$. However, in the chronic phase, the parasitism was only detected by qPCR assay, being higher in the cardiac tissue than in the blood tissue (Table 1).

Our results showed that fexinidazole and posaconazole induced a faster parasitaemia clearance than benznidazole (parasites were not detected at the 6th day of treatment, $16 \mathrm{di}$, by FBE) (Fig. 1a and Table 1). This result was confirmed by qPCR assay, since the parasitaemia detected was several times 
Table 1. Parasite load in benznidazole-, posaconazole- and fexinidazole-treated mice infected with VL-10 Trypanosoma cruzi strain $^{1,2}$

\begin{tabular}{|c|c|c|c|c|}
\hline \multirow[b]{2}{*}{ Treatments ${ }^{2}$} & \multirow[b]{2}{*}{ Days post infection } & \multicolumn{3}{|c|}{$(\text { Parasites mean } \pm \text { s.D. })^{3}$} \\
\hline & & $\mathrm{FBE}^{4}$ & Blood-PCR ${ }^{5}$ & Heart-PCR ${ }^{5}$ \\
\hline Non-treated & $\begin{array}{r}10 \\
16 \\
30 \\
60 \\
120\end{array}$ & $\begin{array}{l}26 \cdot 667 \pm 18 \cdot 09 \\
827 \cdot 333 \pm 532 \cdot 32 \\
113 \cdot 000 \pm 169 \cdot 71 \\
0 \\
0\end{array}$ & $\begin{array}{c}17 \cdot 292 \pm 18 \cdot 75 \\
561 \cdot 038 \pm 237 \cdot 54 \\
149 \cdot 349 \pm 130 \cdot 11 \\
0 \cdot 159 \pm 0 \cdot 18 \\
0 \cdot 175 \pm 0 \cdot 15\end{array}$ & $\begin{array}{c}9 \cdot 596 \pm 10 \cdot 27 \\
26 \cdot 114 \pm 15 \cdot 72 \\
7 \cdot 753 \pm 7 \cdot 33 \\
2 \cdot 609 \pm 1 \cdot 83 \\
0 \cdot 925 \pm 0 \cdot 49\end{array}$ \\
\hline Benznidazole (100 $\mathrm{mg} \mathrm{kg}^{-1}$ day $^{-1}$ ) & $\begin{array}{r}10 \\
16 \\
30 \\
60 \\
120\end{array}$ & $\begin{array}{l}20 \cdot 000 \pm 14 \cdot 53 \\
3 \cdot 333 \pm 3 \cdot 93 \\
0 \\
2 \cdot 000 \pm 2 \cdot 190 \\
0\end{array}$ & $\begin{array}{c}26 \cdot 573 \pm 20 \cdot 02 \\
10 \cdot 912 \pm 8 \cdot 27 \\
0 \cdot 003 \pm 0 \cdot 005 \\
9 \cdot 532 \pm 10 \cdot 75 \\
0 \cdot 614 \pm 0 \cdot 40\end{array}$ & $\begin{array}{l}7 \cdot 200 \pm 15 \cdot 33 \\
0 \cdot 160 \pm 0 \cdot 14 \\
0 \cdot 006 \pm 0 \cdot 014 \\
0 \cdot 059 \pm 0 \cdot 03 \\
0 \cdot 116 \pm 0 \cdot 08\end{array}$ \\
\hline Posaconazole $\left(40 \mathrm{mg}^{-1} \mathrm{~kg} \mathrm{day}^{-1}\right)$ & $\begin{array}{r}10 \\
16 \\
30 \\
60 \\
120\end{array}$ & $\begin{array}{l}14 \cdot 666 \pm 10 \cdot 93 \\
0 \\
0 \\
1 \cdot 333 \pm 2 \cdot 06 \\
0\end{array}$ & $\begin{array}{l}18 \cdot 384 \pm 13 \cdot 69 \\
0 \cdot 017 \pm 0 \cdot 03 \\
0 \\
19 \cdot 669 \pm 12 \cdot 56 \\
1 \cdot 314 \pm 1 \cdot 17\end{array}$ & $\begin{array}{r}10 \cdot 449 \pm 6 \cdot 12 \\
0 \cdot 123 \pm 0 \cdot 13 \\
0 \cdot 029 \pm 0 \cdot 06 \\
2 \cdot 306 \pm 3 \cdot 34 \\
0 \cdot 694 \pm 0 \cdot 88\end{array}$ \\
\hline Fexinidazole (300 $\mathrm{mg} \mathrm{kg}^{-1}$ day $\left.^{-1}\right)$ & $\begin{array}{r}10 \\
16 \\
30 \\
60 \\
120\end{array}$ & $\begin{array}{l}16 \cdot 000 \pm 11 \cdot 86 \\
0 \\
0 \\
0 \\
0\end{array}$ & $\begin{array}{l}23 \cdot 666 \pm 23 \cdot 46 \\
0 \cdot 121 \pm 0 \cdot 26 \\
0 \\
0 \\
0\end{array}$ & $\begin{array}{l}12 \cdot 022 \pm 6 \cdot 32 \\
0 \cdot 119 \pm 0 \cdot 12 \\
0 \\
0 \\
0\end{array}$ \\
\hline
\end{tabular}

1 Swiss female $(n=6)$ weight 18 to 22 g inoculated with $5 \times 10^{3}$ trypomastigotes.

2 Treatment was initiated at 10 day after inoculation followed by 20 days and it was administered per oral route.

3 Data refer to the number of parasites in $0 \cdot 1 \mathrm{~mL}$ of blood or $30 \mathrm{mg}$ of heart tissues $\times 10^{3}$.

4 FBE-fresh blood examination.

5 Real-time PCR in blood (Blood-PCR) and in heart tissues (Heart-PCR).

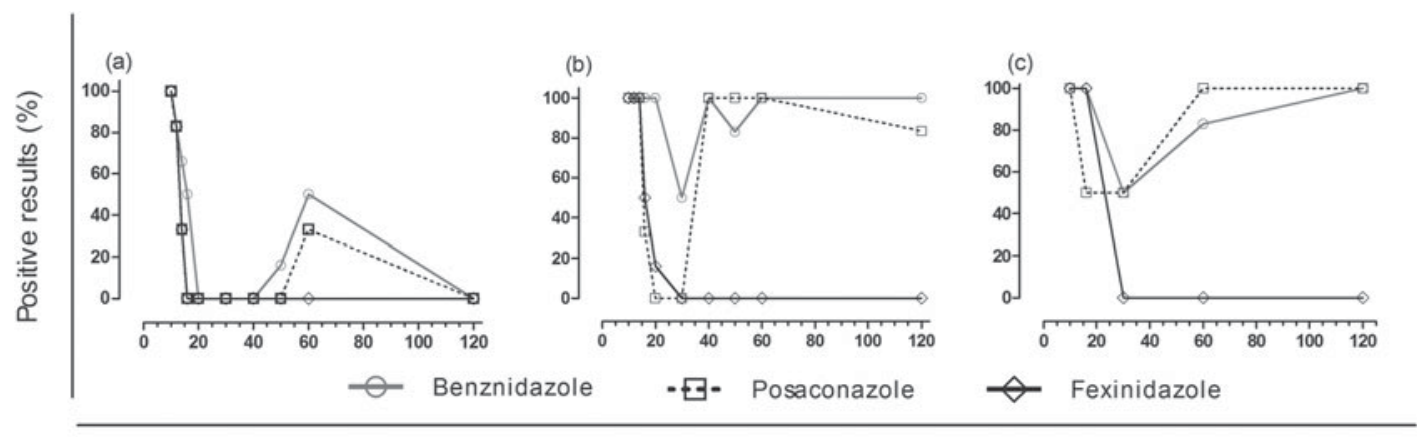

Days post infection

Fig. 1. Trypanosoma cruzi clearance curves. Parasite clearance time in mice infected with VL-10 benznidazole-resistant T. cruzi strain during (10 to $30 \mathrm{di}$ ) and after (40 to $120 \mathrm{di}$ ) benznidazole, posaconazole and fexinidazole treatment. (a) Results determined by fresh blood examination; (b) real-time PCR in blood and (c) in heart tissues of treated mice. $n=6$; di, days of infection.

lower in blood samples of animals treated with fexinidazole (121 parasites $/ 0 \cdot 1 \mathrm{~mL}$ ) and posaconazole (17 parasites $/ 0 \cdot 1 \mathrm{~mL}$ ) than detected in samples collected from benznidazole-treated animals $\left(1 \cdot 09 \times 10^{4}\right.$ parasites $\left./ 0 \cdot 1 \mathrm{~mL}\right)$. At this time, all mice treated with benznidazole had positive parasitaemia in the $\mathrm{qPCR}$ assay, while the same results were detected in $33 \%$ of samples collected in posaconazole and in $50 \%$ of fexinidazole-treated animals (Fig. 1b). Additionally, at the last day of treatment (30 di), the qPCR assay had negative results in all blood samples of fexinidazole- and posaconazole-treated mice
(Fig. 1b). The same result was found in only $50 \%$ of animals treated with benznidazole, and the positive results had lower levels ( 3 parasites $/ 0 \cdot 1 \mathrm{~mL}$ of blood) than the infected and non-treated group $\left(1.49 \times 10^{5}\right.$ parasites $/ 0 \cdot 1 \mathrm{~mL}$ blood) (Table 1 ).

As the clearance of parasites in the peripheral circulation may not always be correlated with the clearance in the tissue, we also evaluated the cardiac parasitism of treated mice. The treatments induced a reduction of cardiac parasite load (119-160 parasites/ $30 \mathrm{mg}$ of heart tissue) at the 6th day of treatment, while in the samples of infected and non-treated 
mice, there were $2.6 \times 10^{4}$ parasites $/ 30 \mathrm{mg}$ of heart tissue ('Table 1). At this time, parasites were detected in $50 \%$ of the tissue samples collected from posaconazole-treated animals and in all of the samples of fexinidazole- and benznidazole-treated mice, suggesting a quick response of posaconazole in the management of tissue parasitism in low or 'controlled' levels during a therapeutic regimen (Fig. 1c), since during the treatment, multiplication of the parasite was low in cardiac tissue, as compared with that observed before treatment, or between nontreated animals (Table 1). However, at the last day of treatment, the qPCR had negative results in all fexinidazole-treated animals, while negative results were detected in only $50 \%$ of those treated with benznidazole and posaconazole (Fig. 1c). Interestingly, our results with posaconazole showed that the parasite clearance was first detected in peripheral blood (Table 1 and Fig. 1a-c). For these mice, at the last day of the treatment, the qPCR had negative results in all blood samples and in $50 \%$ of the tissue samples. However, after the end of the treatment, an increase of parasitism was detected in both peripheral blood and heart tissue samples of animals treated with posaconazole and benznidazole, reaching similar or higher levels than those detected in samples obtained in infected and non-treated animals (Table 1). The parasitaemia reactivation was detected faster in benznidazole-treated animals than in mice treated with posaconazole (Fig. 1a and b). Different data were detected in fexinidazole-treated animals, since after the 6th day of treatment until the end of evaluation (at $120 \mathrm{di}$ ), the $\mathrm{qPCR}$ had negative results (Table 1 and Fig. 1c). Interestingly, the qPCR assay carried out after the end of the treatment with samples of mice treated with benznidazole or posaconazole showed a higher parasitism level in blood than in the cardiac tissue, this result being opposite to that found in the infected and untreated animals (Table 1).

In all experiments, the evaluated compounds were well tolerated by animals and mortality was not detected among treated mice. Additionally, no differences in weight gain were found among treated and non-infected animals during all of the evaluated period (data not shown).

In order to assess the effectiveness of these different treatments in reducing or preventing the development of myocardial lesions in infected mice, a quantitative analysis of inflammation in the heart tissue was performed before treatment $(10 \mathrm{di})$, at the acute $(30 \mathrm{di})$ and chronic $(120 \mathrm{di})$ phases of the infection. Treatments were able to reduce the number of inflammatory cells at the acute phase of experimental T. cruzi infection, as observed by a significant increase of inflammatory infiltrates in the hearts of the infected non-treated animals. However, mice treated with benznidazole presented a higher number of inflammatory cells than the healthy mice
(Fig. 2a). In contrast, fexinidazole and posaconazole treatments prevent heart inflammation, as illustrated by similar levels of inflammatory intensity between treated and healthy animals (Fig. 2a).

The increased parasite loads during the chronic phase of the infection are in line with the increased amount of inflammatory cells in the cardiac tissue of benznidazole- and posaconazole-treated mice. At this time, mice treated with benznidazole and posaconazole had a higher number of inflammatory cells than did the healthy mice (Figs $3 \mathrm{a}$ and 4). Interestingly, the comparison of the number of inflammatory cells in the heart tissue of animals treated with different compounds allowed ordering of the effects of the drugs as follows: (benznidazole < posaconazole $<$ fexinidazole). The means and standard deviations, including the values of controls, were: benznidazole $=$ $286 \cdot 1 \pm 10 \cdot 8$ cells $/ 74931 \mu \mathrm{M}^{2} ;$ posaconazole $=269 \cdot 1 \pm$ $17 \cdot 7$ cells $/ 74931 \mu \mathrm{M}^{2} ; \quad$ fexinidazole $=221 \cdot 4 \pm 13 \cdot 3$ cells $/ 74931 \mu \mathrm{M}^{2}$ and healthy animals $=217 \cdot 5 \pm 23 \cdot 4$ cells/74931 $\mu \mathrm{M}^{2}$. Moreover, analysis of the fibrotic area in the hearts of the treated mice showed that all treatments were efficient in reducing fibrosis in the chronic phase of experimental infection. Interestingly, among animals treated with posaconazole and fexinidazole, a similar heart fibrosis intensity with healthy mice was detected, but significant differences were observed when the heart fibrotic area from healthy and benznidazole-treated mice were compared (Figs $3 \mathrm{~b}$ and 4 ).

We also evaluated the CCL2, CCL5 and NO levels in the plasma of the treated and control animals in order to compare the efficacy of the treatments on the leucocyte chemotractant mediators and NO profiles. The profile of chemokines CCL5 (Fig. 2b) and CCL2 (Fig. 2c) detected in the plasma of infected and non-treated animals was correlated with the parasite load, showing an increase in the early phase of the infection $(10 \mathrm{di})$ peaking at $30 \mathrm{di}$ with plasma levels $\sim 3$-fold (CCL5) and $\sim 6$-fold (CCL2); higher compared with healthy mice. The level of these chemokines was reduced during the chronic phase of infection, but remained significantly higher than those detected in the plasma of healthy mice (Fig. 3c and d). A different pattern was observed in animals treated with the evaluated compounds, and correlated with their anti-T. cruzi activity. At the end of the treatments, the chemokine levels among the treated animals were similar to those detected in healthy animals (Fig. 2b and c). However, at the chronic phase, the chemokine pattern presented particularities according to the compounds used: (i) similar between infected untreated and benznidazole-treated mice; (ii) posaconazole-treated mice had similar CCL2 and smaller CCL5 plasma levels $(P<0 \cdot 05)$ than the infected mice; and (iii) fexinidazole-treated mice had plasma chemokine levels indistinguishable from those of healthy animals (Fig. 3c and d). 

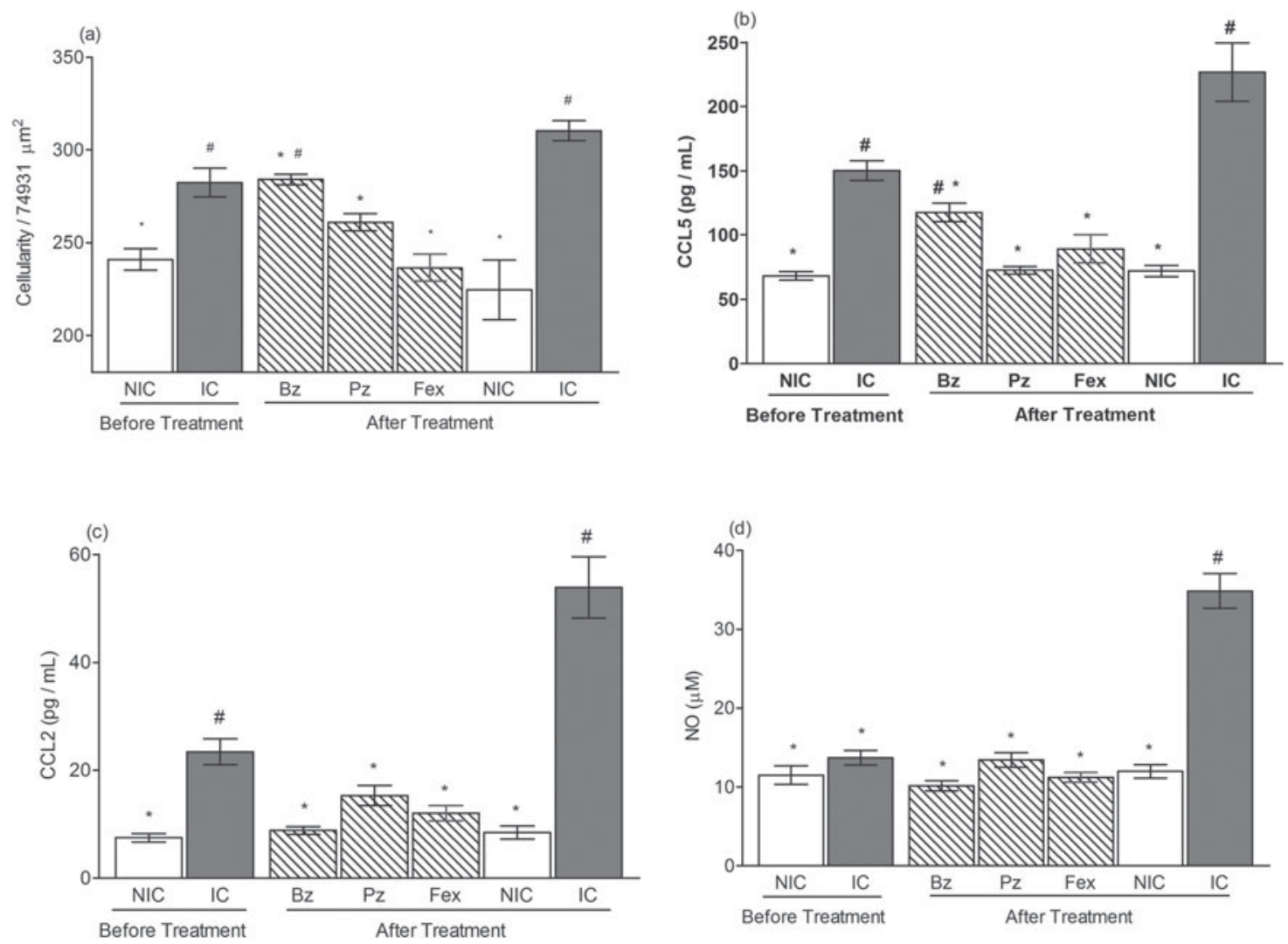

Fig. 2. Inflammatory outcome from treated mice during acute phase of Trypanosoma cruzi infection. Mice were infected with 5000 trypomastigotes of VL-10 strain and treated with benznidazole $(\mathrm{Bz})$, posaconazole $(\mathrm{Pz})$ or fexinidazole (Fex). Animals were euthanized before treatment (10 days of infection) and after treatment (30 days of infection). For controls, infected and non-treated (IC) and non-infected (NIC) groups were evaluated. (a) Myocardial inflammatory cell count in heart muscle of mice. (b) CCL5, (c) CCL2 and (d) NO levels in plasma sample compared with control groups before and after treatment. \# denotes significant differences in relation to non-infected mice $(P<0 \cdot 05)$ * denotes significant differences in relation to infected and non-treated $(P<0 \cdot 05)$.

Levels of $\mathrm{NO}$ were also measured in both phases of infection, as shown in Figs $2 \mathrm{~d}$ and $3 \mathrm{e}$. At $30 \mathrm{di}$, plasma concentrations of $\mathrm{NO}$ reached $\sim 3 \cdot 3$-fold higher than those observed for healthy mice (Fig. 2d). Interestingly, when the parasitism was controlled, there was a decrease in $\mathrm{NO}$, reaching levels similar to those of healthy animals at $120 \mathrm{di}$, and the treated ones, who always had NO levels similar to healthy mice (Fig. 3e).

To confirm the influence of evaluated compounds on CCL2, CCL5 and NO levels, healthy animals were treated using the same therapeutic regime, and chemokines and NO dosages were performed after treatment. Our results showed no significant difference between the chemokines and NO levels detected in the plasma sample of healthy animals, treated or not, showing that drugs used, by themselves, do not interfere in these plasma inflammatory mediators.

\section{DISCUSSION}

Some studies consider that despite their inability to eradicate the parasite, the drug-induced reduction of the parasite loads in infected tissues has positive effects on the clinical evolution of the T. cruzi infection by reducing the severity of the associated inflammatory processes (Andrade et al. 1991; Tarleton et al. 1994; Hardison et al. 2006; Caldas et al. 2008).

To characterize the role of parasite clearance time induced by different treatments and their outcome on Chagas disease, we used $\mathrm{qPCR}$ and defined the dynamic relationship between the efficacy of the treatments and the heart tissue damage during the acute and chronic stages of the infection in mice. In the acute infection, the treatment efficacy to induce parasitic clearance and disease severity showed absolute correlation. Furthermore, drug clearance of parasites induced by the fexinidazole treatment resulted in the disappearance of inflammatory lesions and the resolution of the disease. Previous studies failed to show a correlation between parasitic burden, disease progression and severity ( ̃̃nez et al. 1999; Tarleton and Zhang, 1999; Caldas et al. 2008). Here, the comparisons of blood and tissue parasite loads along the course of infection indicate that all treatments initiated in the acute phase were able to induce a global decrease of parasite loads in both peripheral blood and cardiac tissue, but with 

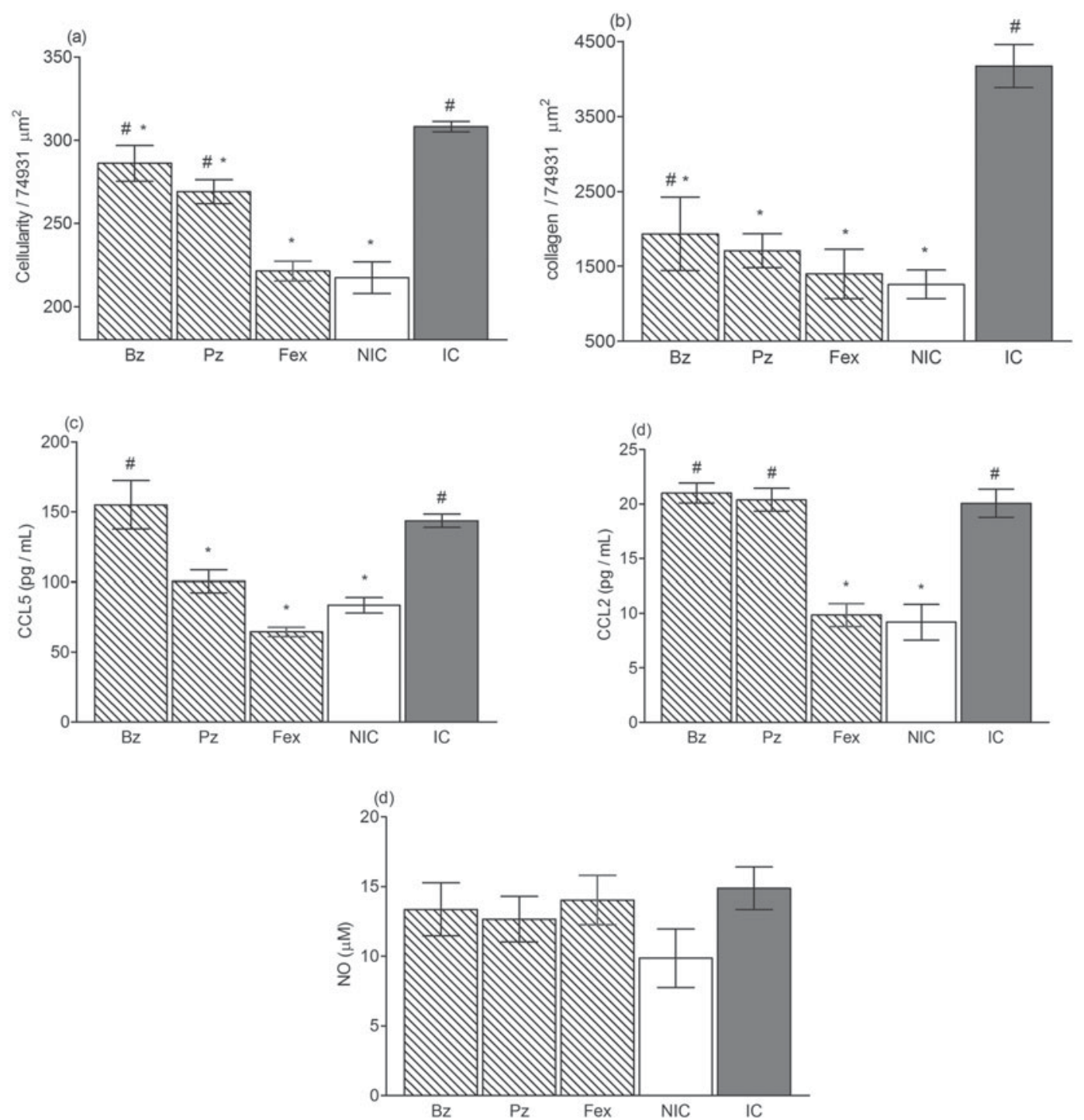

Fig. 3. The outcome of treatment on the development of the chronic phase of experimental Chagas disease. Mice were inoculated with 5000 trypomastigotes of VL-10 strain and treated with benznidazole $(\mathrm{Bz})$, posaconazole $(\mathrm{Pz})$ or fexinidazole (Fex) and euthanized at 90 days after treatment (120 days after inoculation). For controls, infected and nontreated (IC) and non-infected (NIC) groups were evaluated. (a) Myocardial inflammatory cell count in heart muscle of mice. (b) Fibrosis area in heart muscle of mice. (c) CCL5, (d) CCL2 and (e) NO levels in plasma sample of mice compared with control groups, 90 days after treatment. \# denotes significant differences in relation to non-infected mice $(P<0 \cdot 05)$ * denotes significant differences in relation to infected and non-treated $(P<0 \cdot 05)$.

different efficacies. Posaconazole and fexinidazole treatments induced a faster parasite clearance in relation to benznidazole. Among the posaconazoletreated mice, the blood parasite clearance was detected upon both FBE and qPCR. However, the parasites were still detected in $50 \%$ of tissue samples from the heart. These results indicate that the determination of parasite DNA in blood does not reflect the actual parasitic load in cardiac tissue when performed immediately after the end of treatment and it is not sufficient at this time to assess the effect of treatment. As an overall analysis, our results indicated that evaluated compounds presented potent activity against the VL-10 T. cruzi strain, but with individual particularities in their potency. The potent antiT. cruzi activity of fexinidazole could be related to its pharmacokinetic properties. Fexinidazole is rapidly oxidized in vivo in two more therapeutically relevant species, sulphoxide and sulphone metabolites. A high and prolonged systemic bioavailability of these metabolites is achieved a few hours after drug administration (Sokolova et al. 2010). Although both metabolites present anti-T. cruzi activity (Bahia et al. 2014), fexinidazole sulphoxide is extensively converted to sulphone, the final metabolite to appear in the blood. Fexinidazole sulphone presents a better pharmacokinetic profile, as half-life and plasma concentrations, superior to sulphoxide metabolite and benznidazole (Workman et al. 1979; Bahia et al. 2014) and is the species most likely associated with efficacy following administration of fexinidazole. 


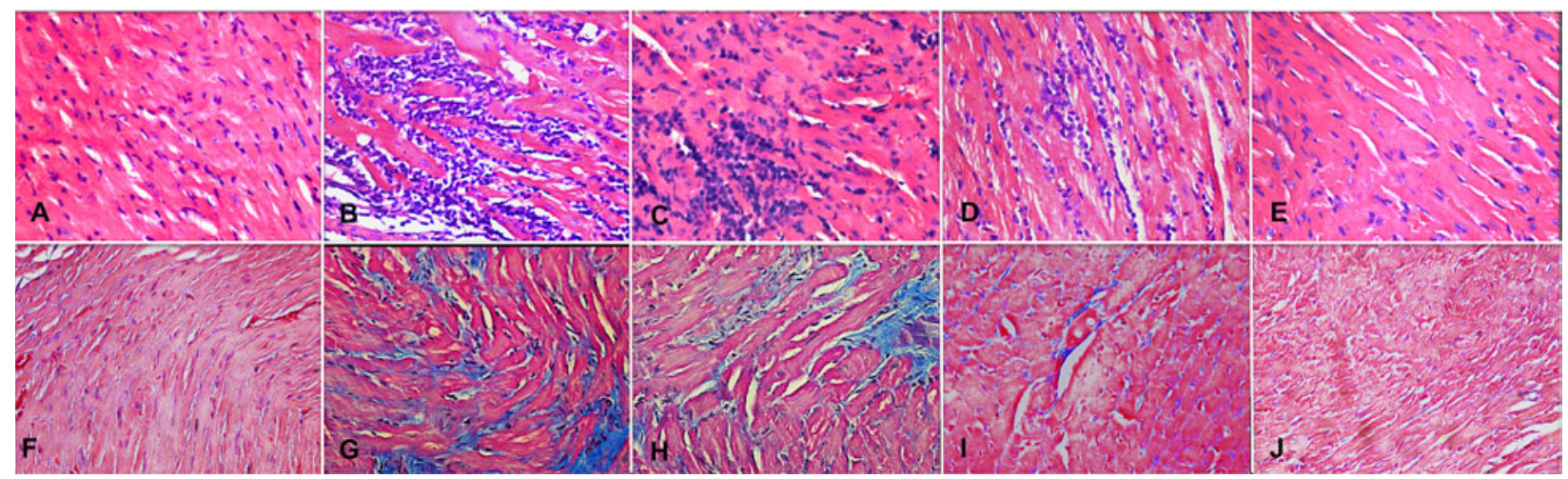

Fig. 4. Treatment reduces chronic Chagas disease-associated inflammatory and fibrotic pathology. Analysis of histological sections of hearts from mice infected with VL-10 strain of Trypanosoma cruzi, $40 \times$ magnification. (A-E) Hematoxylin-eosin staining for inflammation assessment and ( $\mathrm{F}-\mathrm{J}$ ) Masson's trichromic for fibrosis assessment. (A and F) Myocardial sections from healthy mice, (B and $\mathrm{G}$ ) from infected control non-treated mice, $(\mathrm{C}$ and $\mathrm{H})$ from benznidazole-treated mice, (D and I) from posaconazole-treated and (E and J) from fexinidazole-treated mice at 120 days of infection. \# denotes significant differences in relation to non-infected mice $(P<0 \cdot 05)$ * denotes significant differences in relation to infected and non-treated mice $(P<0 \cdot 05)$.

Our data demonstrate that early treatment prevents severe disease progression, due to the control of parasitic replication and its consequent immunopathological implications. Probably, these events induced a balance between the clearance of the parasites and the prevention of the immune-mediated pathology. The degree of regression relates to the successful treatment with cured mice showing the most pronounced reversal of the pathological signs.

In agreement with our data, several authors have shown that even in cases of treatment failure, there was a reduction in the parasitic load as well as in the cardiac lesions, events followed by a slow progression of chronic cardiac injury (Andrade et al. 1991; Garcia et al. 2005; Caldas et al. 2008; Diniz et al. 2010; Santos et al. 2012).

According to Andrade et al. (1991), the presence of the parasite and the inflammatory process underlie the pathological evolution of chronic Chagas disease. In the present work, chemokines and $\mathrm{NO}$ were measured in the plasma samples at the same time that parasitic load and cardiac tissue lesion evaluations were performed. The increased parasite load is in line with the increased amount of CCL2 and CCL5 observed in the plasma of these animals as compared with healthy or cured mice. Interestingly, at the chronic phase, only benznidazole-treated animals presented a significantly higher fibrotic area in the cardiac tissue in comparison with healthy animals, as well as higher levels of CCL2 and CCL5 chemokines. However, the intensity of heart fibrosis was higher in infected and untreated animals, demonstrating the beneficial effect of the reduction of the tissue parasitism induced by different treatments in the disease outcome, even in the absence of parasitological cure. In agreement, a study involving chemokine expression in the heart of chronically T. cruzi-infected beagle dogs with the cardiac form also showed increased mRNA expressions of CXCR3, CCL4 and CCL5 as compared with those in the indeterminate form (Guedes et al. 2004).

In the present study, all evaluated compounds induced a strong reduction in the parasite load, displaying their potent anti-T. cruzi activity. However, a relapse of parasitaemia was detected in benznidazole- and posaconazole-treated mice showing that these compounds were not effective in inducing parasitological cure in mice infected with VL-10 strain. These results were in line with Filardi and Brener (1987) who showed the full resistance of the VL-10 strain to benznidazole. Molina et al. (2000) have reported the efficacy of posaconazole in curing mice infected with benznidazole-resistant T. cruzi strain in a long-term treatment (28 days, 7 days rest and another 15 days). However, a phase II clinical trial to investigate the efficacy and safety of posaconazole in Spain (http://clinicaltrials.gov/ct2/ show/NCT01162967?term=posaconazole) resulted in good safety, but unfortunately, this compound had little to no sustained efficacy in treating patients in the chronic phase of Chagas disease as a single medication (Israel Molina, International Congress of Tropical Medicine http://ictmm2012.ioc.fiocruz.br/ program_25_sept.html). These results highlight the need to investigate alternative dosing regimens and possible combination therapies to improve treatment efficacy. This idea is in line with others; Pinazo et al. (2010) described a successful resolution of a T. cruzi infection (a case of chronic Chagas disease and systemic lupus erythematosus) following treatment with posaconazole $(400 \mathrm{mg}$ for $12 \mathrm{~h}$ during 90 days). Previous treatment of the same patient with benznidazole induced a reduction, but not a complete elimination of the parasite. These results indicate that more prolonged therapeutic regimens may be needed to improve Chagas disease treatment 
efficacy with azoles derivatives. Additionally, the different mechanisms of action and pharmacological characteristics of benznidazole, posaconazole and fexinidazole (Wilkinson and Kelly, 2009; Urbina, 2010; Bahia et al. 2012) might also contribute to explaining the diversified cure rate in VL-10 infected mice. This idea is corroborated by the observations of Guedes et al. (2004) showing that different therapeutic strategies using benznidazole (60-day treatment) and albaconazole (90-day treatment) induced a definitive cure in dogs infected with T.cruzi $\mathrm{Y}$ strain, while the administration of albaconazole for 60 days was able to cure only $25 \%$ (1 of 4 ) of the animals. In this scenario, the individualized therapy schemes, considering both the drug concentration and the time of treatment, might be important for therapeutic success.

Finally, the most important observations of this study were related to the severity of the cardiac lesions in both the acute and chronic phases of the infection and the drug-induced parasitaemia clearance time. These observations suggest that the prevention of $T$. cruzi infection progression in Chagas disease severity might be achieved through chemotherapeutic strategies that enhance parasite clearance and reduce parasite load in a permanent way, thereby contributing to a better balance in the host-parasite relationship.

\section{FINANCIAL SUPPORT}

This study was funded by DND $i$, Fundação de Amparo a Pesquisa do Estado de Minas Gerais and Universidade Federal de Ouro Preto. SC is thankful to FAPEMIG for the BIP fellowship programme. MTB and AT are grateful to the $\mathrm{CNPq}$ research fellowship programme. LFD is thankful to Coordenação de Aperfeiçoamento de Pessoal de Nivel Superior for CAPES/PNPD 2012. DND $i$ would also like to thank the following donors for their support: Department for International Development (DFID), UK; Médecins sans Frontières/Doctors without Borders (MSF), International; Spanish Agency for International Development Cooperation (AECID), Spain; Swiss Agency for Development and Cooperation (SDC), Switzerland; and private foundations and individual donors.

\section{COMPETING INTERESTS}

None to declare.

\section{ETHICAL APPROVAL}

This study was approved by the Ethics Committee in Animal Research at UFOP [number 2009/17].

\section{REFERENCES}

Aliberti, J.C., Machado, F.S., Souto, J.T., Campanelli, A.P., Teixeira, M. M., Gazzinelli, R. T. and Silva, J.S. (1999). Betachemokines enhance parasite uptake and promote nitric oxide-dependent microbiostatic activity in murine inflammatory macrophages infected with Trypanosoma cruzi. Infection and Immunity 67, 4819-4826.
Andrade, S. G., Stocker-Guerret, S., Pimentel, A.S. and Grimaud, J. A. (1991). Reversibility of cardiac fibrosis in mice chronically infected with Trypanosoma cruzi, under specific chemotherapy. Memórias do Insituto Oswaldo Cruz 86, 187-200.

Ãnez, N., Carrasco, H., Parada, H., Crisante, G., Rojas, A., Fuenmayor, C., Gonzales, N., Percoco, G., Borges, R., Guevara, P. and Ramirez, J. L. (1999). Myocardial parasite persistence in chronic chagasic patients. American Yournal of Medicine and Tropical Hygiene 60, $726-732$.

Bahia, M. T., de Andrade, I. M., Martins, T. A., Nascimento, A. F. S., Diniz, L. F., Caldas, I. S., Talvani, A., Trunz, B. B., Torreele, E. and Ribeiro, I. (2012). Fexinidazole: a potential new drug candidate for Chagas disease. PLOS Neglected Tropical Diseases 6, e1870.

Bahia, M.., Nascimento, A.F., Mazzeti, A.L., Marques, L.F., Gonçalves, K. R., Mota, L. W., Diniz, L. F., Caldas, I. S., Talvani, A., Shackleford, D. M., Koltun, M., Saunders, J., White, K. L., Scandale, I., Charman, S. A. and Chatelain, E. (2014). Antitrypanosomal activity of fexinidazole metabolites, potential new drug candidates for Chagas disease. Antimicrobial Agents and Chemotherapy. Epub ahead of print. doi: 10.1128/AAC.02754-13.

Brener, Z. (1962). Therapeutic activity and criterion of cure on mice experimentally infected with Trypanosoma cruzi. Revista Instituto de Medicina Tropical de São Paulo 4, 389-396.

Caldas, I. S., Talvani, A., Caldas, S., Carneiro, C., de Lana, M., Guedes, P. M. M. and Bahia, M. T. (2008). Benznidazole therapy during acute phase of Chagas disease reduces parasite load but does not prevent chronic cardiac lesions. Parasitology Research 103, 413-421.

Caldas, S., Caldas, I. S., Diniz, L. F., Lima, W. G., Oliveira, R. de P., Cecílio, A. B., Ribeito, A., Talvani, A. and Bahia, M. T. (2012). Real-time PCR strategy for parasite quantification in blood and tissue samples of experimental Trypanosoma cruzi infection. Acta Tropica 123, 170-177.

Cançado, J. R. (2000). Long term evaluation of etiological treatment of Chagas disease with benznidazole. Revista do Instituto de Medicina Tropical de São Paulo 44, 29-37.

Cook, D. N., Smithies, O., Strieter, R. M., Frelinger, J.A. and Serody, J. S. (1999). CD8 + T cells are a biologically relevant source of macrophage inflammatory protein-1 alpha in vivo. Fournal of Immunology $162,5423-5428$

Cummings, K. L. and Tarleton, R.L. (2003). Rapid quantitation of Trypanosoma cruzi in host tissue by real-time PCR. Molecular and Biochemical Parasitology 129, 53-59.

Diniz， L.F., Caldas， I. S., Guedes， P. M. M., Crepalde, G.P., de Lana, M., Carneiro, C. M., Talvani, A., Urbina, J.A. and Bahia, M. T. (2010). Effects of ravuconazole treatment on parasite load and immune response in dogs experimentally infected with Trypanosoma cruzi. Antimicrobial Agents and Chemotherapy 54, 2979-2986.

Diniz, L.F., Urbina, J.A., de Andrade, I. M., Mazzetti, A.L., Martins, T.A.F., Caldas, I. S., Talvani, A., Ribeiro, I. and Bahia, M. T. (2013). Benznidazole and posaconazole in experimental Chagas disease: positive interaction in concomitant and sequential treatments. PLOS Neglected Tropical Diseases 7, e2367.

Docampo, R. and Moreno, S. N. J. (1986). Free-radical metabolism of antiparasitic agents. Federation Proceedings 45, 2471-2476.

Filardi, L. S. and Brener, Z. (1987). Susceptibility and natural resistance of Trypanosoma cruzi strains to drugs used clinically in Chagas disease. Transactions of the Royal Society of Tropical Medicine and Hygiene 81, 755-759.

Garcia, S., Ramos, C. O., Senra, J.F., Vilas-Boas, F., Rodrigues, M. M., Campos-de-Carvalho, A.C., Ribeiro-DosSantos, R. and Soares, M. B. (2005). Treatment with benznidazole during the chronic phase of experimental Chagas disease decreases cardiac alterations. Antimicrobial Agents and Chemotherapy 49, 1521-1528.

Guedes, P.M. M., Urbina, J.A., de Lana, M., Afonso, L.C., Veloso, V. M., Tafuri, W. L., Machado-Coelho, G. L., Chiari, E. and Bahia, M. T. (2004). Activity of the new triazole derivative albaconazole against Trypanosoma (Schizotrypanum) cruzi in dog hosts. Antimicrobial Agents and Chemotherapy 48, 4286-4292.

Hardison, J. L., Wrightsman, R. A., Carpenter, P. M., Kuziel, W. A., Lane, T. E. and Manning, J. E. (2006). The CC chemokine receptor 5 is important in control of parasite replication and acute cardiac inflammation following infection with Trypanosoma cruzi. Infection and Immunity $\mathbf{7 4}$, 135-143.

Hall, B. S. and Wilkinson, S. R. (2011). Activation of benznidazole by trypanosomal type I nitroreductases results in glyoxal formation. Antimicrobial Agents and Chemotherapy 56, 115-123.

Machado, F. S., Martins, G. A., Aliberti, J.C., Mestriner, F.L., Cunha, F.Q. and Silva, J.S. (2000). Trypanosoma cruzi-infected 
cardiomyocytes produce chemokines and cytokines that trigger potent nitric oxide-dependent trypanocidal activity. Circulation 102, 3003-3008.

Machado, F. S., Souto, J. T., Rossi, M. A., Esper, L., Tanowitz, H. B., Aliberti, J. and Silva, J. S. (2008). Nitric oxide synthase-2 modulates chemokine production by Trypanosoma cruzi-infected cardiac myocytes. Microbes and Infection 10, 1558-1566.

Molina, J., Martins-Filho, O., Brener, Z., Romanha, A. J., Loebenberg, D. and Urbina, J.A. (2000). Activities of the triazole derivative SCH 56592 (posaconazole) against drug-resistant strains of the protozoan parasite Trypanosoma (Schizotrypanum) cruzi in immunocompetent and immunosuppressed murine hosts. Antimicrobial Agents and Chemotherapy 44, 150-155.

Paiva, C. N., Figueiredo, R. T., Kroll-Palhares, K., Silva, A. A., Silvério, J.C., Gibaldi, D., Pyrrho Ados, S., Benjamim, C.F., Lannes-Vieira, J. and Bozza, M. T. (2009). CCL2/MCP-1 controls parasite burden, cell infiltration, and mononuclear activation during acute Trypanosoma cruzi infection. Fournal of Leukocyte Biology 86, 12391246.

Pinazo, M. J., Espinosa, G., Gállego, M., López-Chejade, P. L., Urbina, J. A. and Gascón, J. (2010). Successful treatment with posaconazole of a patient with chronic Chagas disease and systemic lupus erythematosus. American Fournal of Tropical Medicine and Hygiene 82, 583-587.

Raether, W. and Seidenath, H. (1983). The activity of fexinidazole (HOE 239) against experimental infections with Trypanosoma cruzi, trichomonads and Entamoeba histolytica. Annals of Tropical Medicine and Parasitology 77, 13-26.

Sallusto, F., LanzaVecchia, A. and Mackay, C. R. (1998). Chemokines and chemokine receptors in T-cell priming and Th1/Th2-mediated responses. Immunology Today 19, 568-574.
Santos, F. M., de Lima, W. G., Gravel, A., Martins, T. A., Talvani, A., Torres, R. M. and Bahia, M. T. (2012). Cardiomyopathy prognosis after benznidazole treatment in chronic canine Chagas' disease. Fournal of Antimicrobial Chemotherapy 68, 1-9.

Sokolova, A. Y., Wyllie, S., Patterson, S., Oza, S. L., Read, K. D. and Fairlamb, A. H. (2010). Cross-resistance to nitro drugs and implications for treatment of human African trypanosomiasis. Antimicrobial Agents and Chemotherapy 54, 2893-2900.

Talvani, A., Ribeiro, C.S. and Aliberti, J. C. S. (2000). Kinetics of cytokine genes expression in experimental chagasic cardiomyopathy: a direct correlation between levels of tissue parasitism and chemokine mRNAs expression during infection with Trypanosoma cruzi. Microbes and Infection 2, 851-866.

Tarleton, R. L. and Zhang, L. (1999). Chagas disease etiology: autoimmunity or parasite persistence? Parasitology Today 15, 94-99.

Tarleton, R. L., Sun, J., Zhang, L. and Postan, M. (1994). Depletion of T-cell subpopulations results in exacerbation of myocarditis and parasitism in experimental Chagas' disease. Infection and Immunity 62, 1820-1829.

Torreele, E., Trunz, B. B., Tweats, D., Kaiser, M., Brun, R. Mazué, G., Bray, M. A. and Pécoul, B. (2010). Fexinidazole: a new oral nitroimidazole drug candidate entering clinical development for the treatment of sleeping sickness. PLOS Neglected Tropical Diseases 4, e923.

Urbina, J. A. (2010). Specific chemotherapy of Chagas disease: relevance, current limitations and new approaches. Acta Tropica 115, 55-68. Wilkinson, S. R. and Kelly, J. M. (2009). Trypanocidal drugs: mechanisms, resistance and new targets. Expert Reviews in Molecular Medicine $\mathbf{1 1}$ e31

Workman, P., White, R.A., Walton, M. I., Owen, L.N. and Twentyman, P. R. (1979). Preclinical pharmacokinetics of benznidazole. British Fournal of Cancer 50, 291-303. 